Bull. Chem. Soc. Ethiop. 2019, 33(2), 243-254.

ISSN 1011-3924

(c) 2019 Chemical Society of Ethiopia and The Authors

Printed in Ethiopia

DOI: https://dx.doi.org/10.4314/bcse.v33i2.5

\title{
KINETIC AND THERMODYNAMIC STUDY OF OXIDATIVE DEGRADATION OF ACID YELLOW 17 DYE BY FENTON-LIKE PROCESS: EFFECT OF $\mathrm{HCO}_{3}{ }^{-}, \mathrm{CO}_{3}{ }^{2-}$, $\mathrm{Cl}^{-} \mathrm{AND} \mathrm{SO}_{4}{ }^{2-}$ ON DYE DEGRADATION
}

\author{
Jehangeer Khan ${ }^{1}$, Muhammad Tariq ${ }^{1 *}$, Mamriz Muhammad ${ }^{1}$, Muhammad Haris Mehmood ${ }^{1}$, \\ Inam Ullah ${ }^{1}$, Abdur Raziq ${ }^{1}$, Fazli Akbar ${ }^{1}$, Muhammad Saqib ${ }^{1}$, Abdur Rahim ${ }^{2}$ and Abdul Niaz ${ }^{3}$ \\ ${ }^{1}$ National Centre of Excellence in Physical Chemistry, University of Peshawar-25120, Pakistan \\ ${ }^{2}$ Interdisciplinary Research Centre in Biomedical Materials (IRCBM), COMSATS University \\ Islamabad, Lahore Campus \\ ${ }^{3}$ Department of Chemistry, Hazara University, Mansehra-21120, Pakistan
}

(Received July 6, 2018; Revised February 27, 2019; Accepted April 4, 2019)

\begin{abstract}
We report here the degradation of AY-17 dye using Fenton-like process $\left(\mathrm{H}_{2} \mathrm{O}_{2} / \mathrm{Fe}^{3+}\right)$. The maximum degradation (83\%) of AY17 dye is achieved at pH 3 in $60 \mathrm{~min}$, with optimum concentrations of AY 17 $(0.06 \mathrm{mM}), \mathrm{H}_{2} \mathrm{O}_{2}(0.9 \mathrm{mM})$, and $\mathrm{Fe}^{2+}(0.06 \mathrm{mM})$. The scavenging effects of $\mathrm{HCO}_{3}{ }^{-}, \mathrm{CO}_{3}{ }^{2-}, \mathrm{Cl}^{-}$and $\mathrm{SO}_{4}{ }^{2-}$ on dye degradation are also examined. The activation energy $\left(E_{a}\right)$, activation enthalpy $\left(\triangle \mathrm{H}^{*}\right)$, and activation entropy $\left(\triangle S^{*}\right)$ are calculated for the dye degradation using pseudo-first-order kinetics at various temperature.
\end{abstract}

KEY WORDS: Acid Yellow 17, $\mathrm{H}_{2} \mathrm{O}_{2} / \mathrm{Fe}^{3+}$, Fenton-like process, Oxidative degradation, Scavenging effects

\section{INTRODUCTION}

The azo dyes are frequently used in textile industries due to its low energy consumption, easy utilization, high stability during washing and it presence in varieties of color. A huge amount of water is consumed by textile and dyeing industries. The resulting wastewater from these industries may contain reactive azo dyes and its intermediates. The direct discharge of these dyes-contaminated waste water (from these industries) to water bodies may produce a severe environmental problem. Even, a small quantity $(1 \mathrm{mg} / \mathrm{L})$ of these dyes might produce an adverse effect on environment. These dyes contaminated water might be harmful for both aquatic and human life, producing hazardous mutagenic or carcinogenic effect in human being $[1,2]$. The discharge of dyes into water, depressed photosynthesis as well as respiration processes of aquatic system [3]. Hence, the treatment of water containing these hazardous pollutants is a major issue for environmental chemist [4-7]. Generally, these azo dyes are non-biodegradable in aerobic condition and convert to more toxic intermediate [8]. Various adsorbents and biosorbents have been used for removal of these dyes [9-11]. Ranjithkumar et al. [9] reported the use of activated carbon/ $\mathrm{Fe}_{2} \mathrm{O}_{3}$ nanocomposite as adsorbent for removal of acid yellow 17 . Similarly, Ashraf et al. [10] used a plant named T. Angustata L. and Gao et al. [11] used nonliving aerobic granular sludge as biosorbent for removal of acid yellow 17 dye.

For the last two decades, AOPs have been playing an important role in the degradation of azo dyes [12-14]. In these processes high oxidizing agent ${ }^{\circ} \mathrm{OH}$ radical (having redox potential $2.8 \mathrm{~V}$ vs SHE) are used to oxidize the dyes. AOPs degraded complex structured dyes to smaller organic molecules or may completely oxidized it to $\mathrm{CO}_{2}$ and $\mathrm{H}_{2} \mathrm{O}[15,16]$.

AOPs includes, Fenton, photo-Fenton, homogenous Fenton-like process, $\mathrm{TiO}_{2} / \mathrm{UV}$ [17], $\mathrm{ZnO} / \mathrm{UV}$ [18], ozonation [19], etc. Among them, Fenton process $\left(\mathrm{Fe}^{2+} / \mathrm{H}_{2} \mathrm{O}_{2}\right)$ is the commonly used for degradation of dyes and other organic pollutants. Because, it has many advantages: (1) it involves the breakdown of $\mathrm{H}_{2} \mathrm{O}_{2}$ into environmental friendly species such as $\mathrm{O}_{2}$ and $\mathrm{H}_{2} \mathrm{O}$, (2) it is a non-toxic process [20], (3) and it is simple, it can be employed at STP and (4) and yield

*Corresponding author.dr.muhammadtariq@uop.edu.pk, tariq_ftj@yahoo.com

This work is licensed under the Creative Commons Attribution 4.0 International License 
high efficiency [21]. Our group has already reported AY-17 dye removal by $\mathrm{Fe}^{2+} / \mathrm{H}_{2} \mathrm{O}_{2}$ and $\mathrm{UV} / \mathrm{Fe}^{2+} / \mathrm{H}_{2} \mathrm{O}_{2}$ system $[22,23]$. However, there are some disadvantages associated with these process [24]. To overcome these disadvantages, the modified Fenton processes were introduced - the $\mathrm{Fe}^{2+}$ were replaced with nano zero valent iron or $\mathrm{Fe}^{3+}[25,26]$.

In the present study Fenton-like process, $\mathrm{H}_{2} \mathrm{O}_{2} / \mathrm{Fe}^{3+}$, were used for degradation of AY 17 in aqueous medium. The optimum concentration of $\mathrm{H}_{2} \mathrm{O}_{2}, \mathrm{Fe}^{3+}$, and $\mathrm{AY} 17$ were determined for achieving high degradation efficiency. The effects of $\mathrm{pH}$, temperature and various anions $\left(\mathrm{CO}_{3}{ }^{2-}, \mathrm{HCO}_{3}{ }^{-}, \mathrm{Cl}^{-}\right.$and $\left.\mathrm{SO}_{4}{ }^{2-}\right)$ on the efficiency of dye degradation were investigated. Kinetic study of dye degradation reaction was also carried out.

\section{EXPERIMENTAL}

\section{Chemical and reagent}

Acid Yellow 17 (dye content 60\%) was obtained from Acros Organics. Hydrogen peroxide $(30 \% \mathrm{w} / \mathrm{w})$, ferric sulfate hepta hydrated, sodium carbonate, sodium sulfate, sulfuric acid, sodium chloride, hydrochloric acid, and sodium hydroxide analytical grade from Sigma Aldrich were used as received.

\section{Experimental procedure}

Ultra-pure water (resistivity $\geq 18.2 \mathrm{M} \Omega$. cm), purify through Milli- $\mathrm{Q}^{\circledR}$ purification system was used for preparation of solutions. The UV-Vis spectra of AY 17 in a quartz cell $(1 \mathrm{~cm}$ path length) were recorded in the range of 300-700 nm using a UV-visible spectrophotometer (Perkin Elmer, Model: Lambda-650, UK). All the experiments were performed in triplicate at room temperature. The $\mathrm{pH}$ of solutions was adjusted through $\mathrm{pH}$ meter; NeoMet ISTEC (Korea), using $\mathrm{HCl}$ and $\mathrm{NaOH}$. Experiments were carried out in $50 \mathrm{~mL}$ beakers in thermostat of constant temperature. The experimental mixture is stirred by magnetic stirrer. In each experiment certain quantity of dye ferric ion $\left(\mathrm{Fe}^{3+}\right)$, and $\mathrm{H}_{2} \mathrm{O}_{2}$ were put in a volumetric flask and then diluted up to $50 \mathrm{ml}$ by adding triply distilled water. The samples were instantly analyzed at fixed time intervals. The change in $\lambda_{\max }$ was monitored at consecutive time interval to study the course of the degradation process.

The change in concentration of AY 17 was determined from the absorbance intensity of reaction mixture (at $400 \mathrm{~nm}, \varepsilon=12928 \mathrm{M}^{-1} \mathrm{~cm}^{-1}$ ) at various time intervals through the calibration plot. The absorption of reaction mixture and sampling were completed within one minute to minimize experimental error [27]. Percent degradation was calculated using Eq. (1).

Percent Degradation (\%) $=\left(1-\frac{C_{t}}{C_{0}}\right) \times 100 \%$

\section{RESULTS AND DISCUSSION}

Degradation of $\mathrm{AY} 17$ by ferric ion $\left(\mathrm{Fe}^{3+}\right)$, hydrogen peroxide $\left(\mathrm{H}_{2} \mathrm{O}_{2}\right)$, and Fenton-like process $\left(\mathrm{H}_{2} \mathrm{O}_{2} / \mathrm{Fe}^{3+}\right)$ : selection of suitable system

The effect of various parameters on percent degradation of AY 17 was investigated (Figure 1). The maximum dye degradation was obtained in 60 minutes with optimal concentrations of $\mathrm{H}_{2} \mathrm{O}_{2}$ $(0.9 \mathrm{mM}), \mathrm{Fe}^{3+}(0.06 \mathrm{mM})$, and AY $17(0.06 \mathrm{mM})$ dye (see next sections). Foremost, AY 17 $(0.06 \mathrm{mM})$ was degraded using individual $\mathrm{H}_{2} \mathrm{O}_{2}$ and $\mathrm{Fe}^{3+}$ systems and then Fenton like $-\mathrm{H}_{2} \mathrm{O}_{2}$ $/ \mathrm{Fe}^{3+}$ system were applied. It was observed that the degradation of acid yellow 17 dye with $\mathrm{Fe}^{3+}$, $\mathrm{H}_{2} \mathrm{O}_{2}$, and $\mathrm{Fe}^{3+} / \mathrm{H}_{2} \mathrm{O}_{2}$ systems were about $3 \%, 11 \%$ and $83 \%$, respectively in 60 minutes. The reason for low percent degradation of dye solutions through individual $\mathrm{Fe}^{3+}$ or $\mathrm{H}_{2} \mathrm{O}_{2}$ systems 
were due to the low quantity of hydroxyl radical production because of the absence of an oxidizing agent, $\mathrm{H}_{2} \mathrm{O}_{2}\left(\mathrm{Fe}^{3+}\right.$ system) or catalyst, $\mathrm{Fe}^{3+}$ in $\left(\mathrm{H}_{2} \mathrm{O}_{2}\right.$ system) while, high percent dye degradation in $\mathrm{Fe}^{3+} / \mathrm{H}_{2} \mathrm{O}_{2}$ system was due to production of large amount of hydroxyl radical $\left({ }^{\bullet} \mathrm{OH}\right)$ because of the presence of both oxidizing and reducing species [28]. The general mechanism for hydroxyl radical $\left({ }^{\bullet} \mathrm{OH}\right)$ generation is given by Eq. 2 and 3 [29].

$$
\begin{aligned}
& \mathrm{Fe}^{3+}+\mathrm{H}_{2} \mathrm{O}_{2} \rightarrow \mathrm{Fe}^{2+}+\mathrm{HOO}^{\bullet}+\mathrm{H}^{+} \\
& \mathrm{Fe}^{2+}+\mathrm{H}_{2} \mathrm{O}_{2} \rightarrow \mathrm{Fe}^{3+}+\mathrm{HO}^{\bullet}+\mathrm{HO}^{-}
\end{aligned}
$$

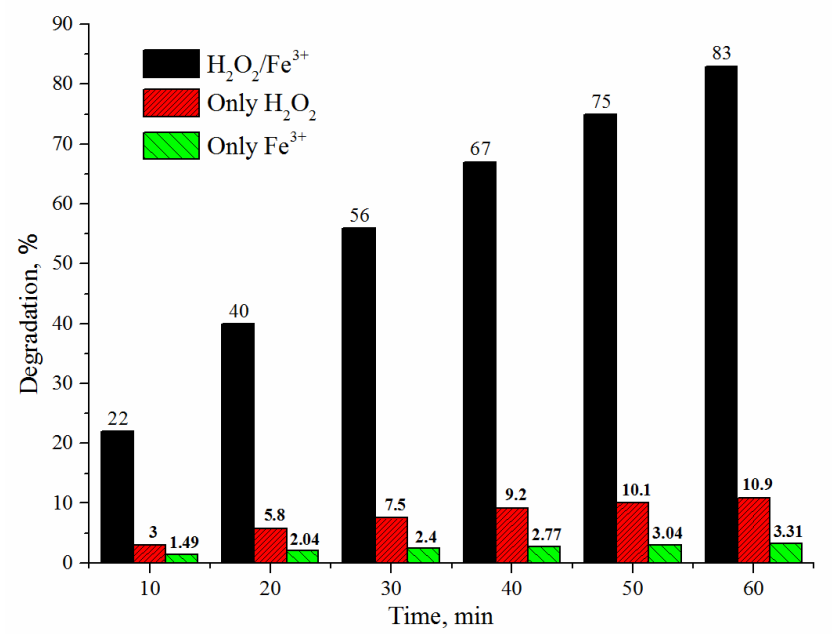

Figure 1. Selection of suitable process for degradation of AY 17 dye: $\mathrm{pH}=3.0,\left[\mathrm{H}_{2} \mathrm{O}_{2}\right]_{\mathrm{o}}=0.9$ $\mathrm{mM},[\mathrm{AY} 17]_{\mathrm{o}}=\left[\mathrm{Fe}^{3+}\right]_{\mathrm{o}}=0.06 \mathrm{mM}, \mathrm{T}=298 \mathrm{~K}$.

\section{Effect of $\mathrm{pH}$ dye degradation}

As the $\mathrm{pH}$ plays an important role in the degradation of dye solution. Hence, dye solutions of $\mathrm{pH}$ 2.0, 3.0, 6.0, and 8.0 were degraded using Fenton-like process for $60 \mathrm{~min}$. The initial concentration of acid yellow $17, \mathrm{H}_{2} \mathrm{O}_{2}$ and ferric ion were taken as $0.06,0.9$, and $0.06 \mathrm{mM}$, for acid yellow 17, $\mathrm{H}_{2} \mathrm{O}_{2}$ and $\mathrm{Fe}^{3+}$, respectively (Figure 2a). It was observed that highest percent degradation $(83 \%)$ was achieved at $\mathrm{pH} 3.0$. The reason for such a high degradation efficiency was the high production of hydroxyl radical $\left({ }^{\circ} \mathrm{OH}\right)$ by $\mathrm{Fe}^{3+}$ at $\mathrm{pH} 3.0$ [30].

The low oxidative degradation of acid yellow 17 dye at pH 6.0 and 8.0 might be explained by several facts: Firstly, the formation of $\mathrm{Fe}(\mathrm{OH})_{3}$ which has low catalytic properties in decomposition of hydrogen peroxide $\left(\mathrm{H}_{2} \mathrm{O}_{2}\right)$ [31]. Secondly, the decrease in number of free iron species in solution because at high $\mathrm{pH}(6.0$ and 8.0$)$ precipitation of polymeric ferric oxy hydroxides occurred [32]. The activity of oxy hydroxides might be very low and it may hindered ferrous ion $\left(\mathrm{Fe}^{2+}\right)$ production for hydroxyl radical $\left({ }^{\circ} \mathrm{OH}\right)$ generation shown by Eq. 2 and 3 [33]. Another possibility for low oxidation was the formation of ferrous complexes, which also hindered the reaction of ferric ion $\left(\mathrm{Fe}^{3+}\right)$ with hydrogen peroxide [34]. Similarly, the low percent degradation of acid yellow 17 dye at $\mathrm{pH} \sim 2.0$ was either due to the formation of iron complex species such as $\left.\left[\mathrm{Fe}(\mathrm{II})\left(\mathrm{H}_{2} \mathrm{O}\right)_{6}\right]^{2+}\right)$ or scavenging of the hydroxyl $\left({ }^{\bullet} \mathrm{OH}\right)$ radical hydronium ion $\left(\mathrm{H}_{3} \mathrm{O}^{+}\right)$at low $\mathrm{pH}[33,35]$. 
Effect of initial concentration of $\left(\mathrm{H}_{2} \mathrm{O}_{2}\right)$

The effect of $\mathrm{H}_{2} \mathrm{O}_{2}$ concentration over dye degradation was also checked. A series of $0.06 \mathrm{mM}$ dye solutions containing various concentrations (i.e. 0.5, 0.6, 0.9 and $1.10 \mathrm{mM}$ ) of $\mathrm{H}_{2} \mathrm{O}_{2}$ and constant initial concentration of $\mathrm{Fe}^{3+}$ at $\mathrm{pH} 3$ ware degraded to determine the initial optimum dose of $\mathrm{H}_{2} \mathrm{O}_{2}$ for maximum degradation of AY 17 (Figure 2b). The dye was oxidized through - $\mathrm{OH}$ radical produced via the reaction of hydrogen peroxide with $\mathrm{Fe}^{3+}$ (Fenton-like process). The mechanism for reaction of $\mathrm{Fe}^{3+}$ with $\mathrm{H}_{2} \mathrm{O}_{2}$ can be found elsewhere in literature [36-39].
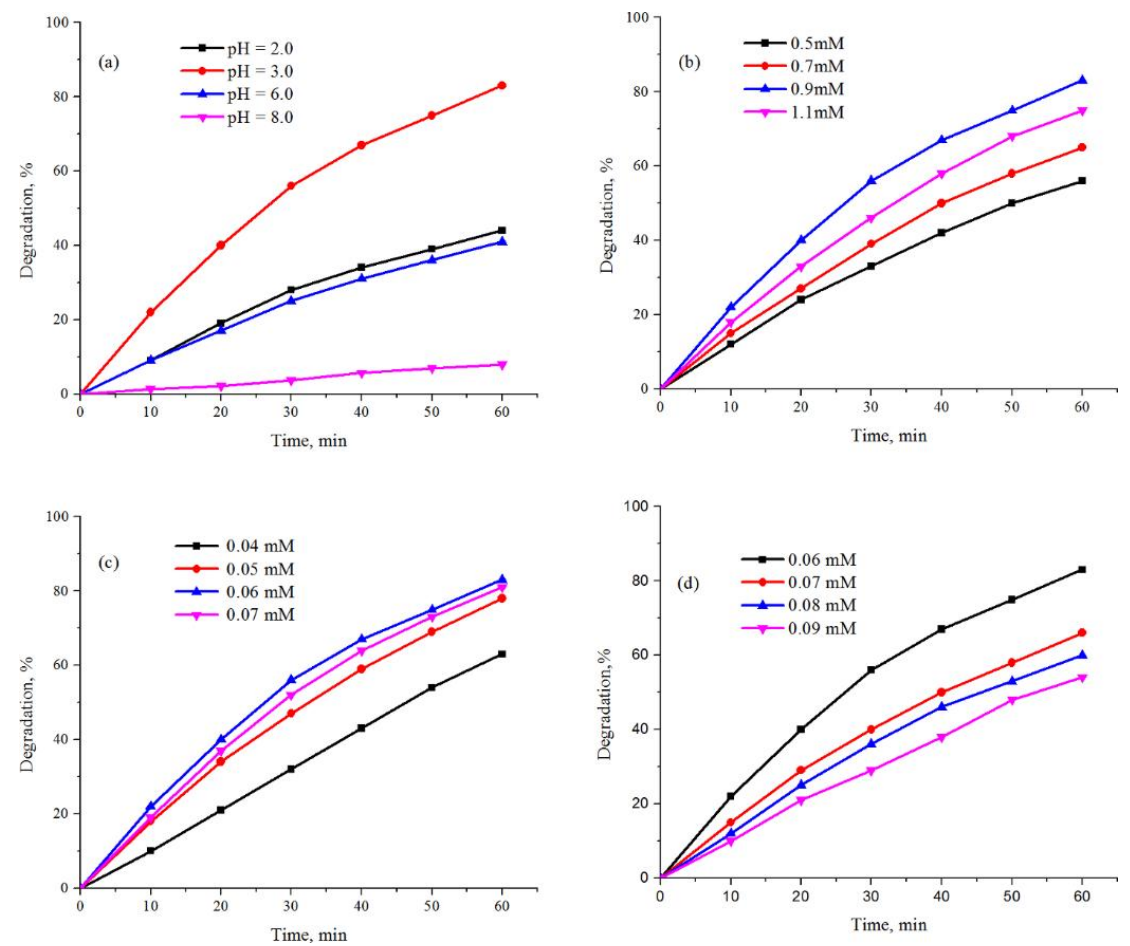

Figure 2. Effect of various conditions on \% degradation of AY 17 by Fenton-like process: (a) $\mathrm{pH}$, (b) $\mathrm{H}_{2} \mathrm{O}_{2}$, (c) $\mathrm{Fe}^{2+}$, (d) concentration of dye. The optimized reaction conditions were determined as: $\left[\mathrm{H}_{2} \mathrm{O}_{2}\right]_{\mathrm{o}}=0.9 \mathrm{mM},\left[\mathrm{Fe}^{2+}\right]_{\mathrm{o}}=[\mathrm{AY} 17]_{\mathrm{o}}=0.06 \mathrm{mM}, \mathrm{pH}=3.0$.

It was observed that degradation of AY 17 dye increases with hydrogen peroxide concentration. Optimal concentration of $\mathrm{H}_{2} \mathrm{O}_{2}$ for high degradation $(83 \%)$ was found to be 0.9 $\mathrm{mM}$. it was also observed that further increase in $\mathrm{H}_{2} \mathrm{O}_{2}$ concentration decreased the percent degradation which might be due to scavenging of ${ }^{\bullet} \mathrm{OH}$ radical by $\mathrm{H}_{2} \mathrm{O}_{2}$, hydroperoxy radical $\left(\mathrm{OOH}^{*}\right)$, form during $\mathrm{H}_{2} \mathrm{O}_{2} / \mathrm{Fe}^{3+}$ reaction or dimerization of hydroxyl radical $\left({ }^{\circ} \mathrm{OH}\right)$ with itself as given by equation (4-6) [37, 40].

$$
\begin{array}{lll}
\mathrm{H}_{2} \mathrm{O}_{2}+{ }^{\bullet} \mathrm{OH} \rightarrow \mathrm{H}_{2} \mathrm{O}+\mathrm{OOH}^{\bullet} & k=2.7 \times 10^{7} \mathrm{M}^{-1} \mathrm{~s}^{-1} \\
\mathrm{OOH}^{\bullet}+{ }^{\bullet} \mathrm{OH} \rightarrow \mathrm{H}_{2} \mathrm{O}+\mathrm{O}_{2} & k=7.1 \times 10^{9} \mathrm{M}^{-1} \mathrm{~s}^{-1} \\
{ }^{\bullet} \mathrm{OH}+{ }^{\bullet} \mathrm{OH} \rightarrow \mathrm{H}_{2} \mathrm{O}_{2} & & k=6.0 \times 10^{9} \mathrm{M}^{-1} \mathrm{~s}^{-1}
\end{array}
$$




\section{Effect of initial concentration of ferric ion $\left(\mathrm{Fe}^{3+}\right)$}

As the production of ${ }^{\bullet} \mathrm{OH}$ radicals by hydrogen peroxide is catalyzed by iron $\left(\mathrm{Fe}^{3+}\right)$, therefore, the optimum concentration of $\mathrm{Fe}^{3+}$ for maximum dye degradation was also determined at $\mathrm{pH} 3$. Here, the initial concentration of dye $(0.06 \mathrm{mM})$ and $\mathrm{H}_{2} \mathrm{O}_{2}(0.9 \mathrm{mM})$ were kept fixed. While concentration of $\mathrm{Fe}^{3+}$ was altered from $0.04 \mathrm{mM}$ to $0.06 \mathrm{mM}$ (Figure $2 \mathrm{c}$ ). It was observed that the percent degradation of AY 17 dye increased from $63 \%$ to $83 \%$ upon increasing $\mathrm{Fe}^{3+}$ concentration. However, further increase in $\mathrm{Fe}^{3+}$ concentration decreased down the \% degradation due to scavenging of ${ }^{\bullet} \mathrm{OH}$ radical by $\mathrm{Fe}^{2+}$. The ratio/proportion of $\mathrm{H}_{2} \mathrm{O}_{2}: \mathrm{Fe}^{3+}$ is also important in degradation of dye solution because it was reported that in $\mathrm{H}_{2} \mathrm{O}_{2} / \mathrm{Fe}^{3+}$ system the concentration of $\mathrm{Fe}^{2+}$ increased quickly and then attain "steady state" with passage of time. In fact, the addition of $\mathrm{Fe}^{3+}$ to a system containing $\mathrm{H}_{2} \mathrm{O}_{2}$ lead to formation of $\mathrm{Fe}^{3+}$ peroxo complexes which convert into $\mathrm{Fe}^{2+}$ and $\mathrm{HO}_{2}{ }_{2}$ Eq. (7-8) [33]. Hence, the scavenging of hydroxyl radical by hydrogen peroxide and $\mathrm{Fe}^{2+}$ depends on the molar ratio of $\mathrm{H}_{2} \mathrm{O}_{2}$ and $\mathrm{Fe}^{3+}$ [33].

$$
\begin{aligned}
& \mathrm{Fe}-\mathrm{OOH}{ }^{2+}+\mathrm{H}_{2} \mathrm{O}_{2} \rightarrow \mathrm{Fe}(\mathrm{OH})_{2}\left(\mathrm{HO}_{2}\right)^{+} \\
& \mathrm{Fe}(\mathrm{OH})\left(\mathrm{HO}_{2}\right)^{+} \rightarrow \mathrm{Fe}^{2+}+\mathrm{HO}_{2}^{\bullet}+\mathrm{OH}^{-} \\
& \text {Dye concentration effect on degradation }
\end{aligned}
$$

\section{Dye concentration effect on degradation}

The concentration of AY 17 dye is also important parameter which effects the percent degradation. Effect of initial concentration of dye on the degradation was shown in Figure 2d. By keeping the initial concentration of $\left[\mathrm{H}_{2} \mathrm{O}_{2}\right]=0.90 \mathrm{mM}$ and $\left[\mathrm{Fe}^{3+}\right]=0.06 \mathrm{mM}$, it was monitored that the percent degradation decreased from $83 \%$ to $54 \%$ upon increasing AY 17 concentrations which is in agreement with previous reports [41].

The high degradation of AY 17 at low concentration $(0.06 \mathrm{mM})$ of dye was due to the frequent availability of hydroxyl $\left({ }^{\bullet} \mathrm{OH}\right)$ radical for low amount of dye molecule. Hence, the decreases in percent degradation $(54 \%)$ at comparatively high concentration $(0.09 \mathrm{mM})$ of dye might be interpreted in term of the inadequate availability of hydroxyl radical for AY 17 molecules degradation [27].

\section{Effect of $\mathrm{CO}_{3}{ }^{2-}$ and $\mathrm{HCO}_{3}{ }^{-}$on the $\mathrm{AY} 17$ percent degradation}

A large amount of inorganic salts, like $\mathrm{Na}_{2} \mathrm{CO}_{3}$ and $\mathrm{NaHCO}_{3}$ are commonly used in various dying process. The presence of these inorganic ions may affect the degradation of AY 17 dye. The influence of $\mathrm{CO}_{3}{ }^{2-}$ and $\mathrm{HCO}_{3}{ }^{-}$on degradation of acid yellow 17 dye was investigated at $\mathrm{pH}$ 3. Figure 3 shows the degradation of dye solutions in presence of different concentrations of anions; $\mathrm{HCO}_{3}{ }^{-}$and $\mathrm{CO}_{3}{ }^{2-}$. It was observed that the presence of these ions has a negative effect on dye degradation. The percent degradation of AY 17 decreased from $83 \%$ to $66 \%$ in case of $\mathrm{CO}_{3}{ }^{2-}$ while $70 \%$ in case of $\mathrm{HCO}_{3}^{-}$. These results agree with literature [42]. These ions are much stable and do not form complexes with iron [43], hence, they are able to scavenge the hydroxyl radical $\left({ }^{\circ} \mathrm{OH}\right)$ although another radical, $\mathrm{CO}_{3}{ }^{--}$, produced in the hydroxyl radical $\left({ }^{\bullet} \mathrm{OH}\right)$ scavenging reaction, but, it has much less reactivity than hydroxyl radical [44].

Effect of $\mathrm{Cl}^{-}$and $\mathrm{SO}_{4}{ }^{2-}$ on the $\mathrm{AY} 17$ percent degradation

The effect of chloride $\left(\mathrm{Cl}^{-}\right)$and sulfate $\left(\mathrm{SO}_{4}{ }^{2-}\right)$ ions on dye degradation were investigated (Figure 4). It was noted that percent degradation diminished in the presence of these anions which is due to the scavenging of hydroxyl radical by these anions. The quenching ability of these anions also depends on the nature of these anions, concentration, and type of oxidant (i.e. $\mathrm{H}_{2} \mathrm{O}_{2}$ ) used for dye oxidation/degradation [45]. 
These anions also form stable complexes with $\mathrm{Fe}^{3+} / \mathrm{Fe}^{2+}$, therefore, the concentration of $\mathrm{Fe}^{3+} / \mathrm{Fe}^{2+}$ decreased in the system which results decrease in hydroxyl radical formation.
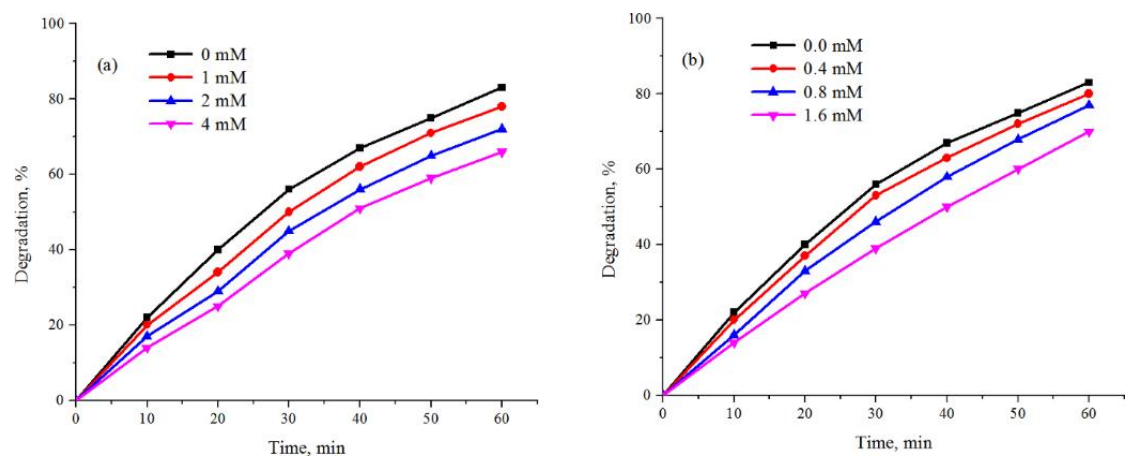

Figure 3. Effect of carbonate, $\mathrm{CO}_{3}{ }^{2-}$ (a) and bicarbonate, $\mathrm{HCO}_{3}{ }^{-}$(b) ion on $\%$ degradation of acid yellow 17 dye in Fenton-like process. Other experimental condition: $\left[\mathrm{Fe}^{3+}\right]_{\mathrm{o}}=[\mathrm{AY}$ $17]_{\mathrm{o}}=0.06 \mathrm{mM},\left[\mathrm{H}_{2} \mathrm{O}_{2}\right]_{\mathrm{o}}=0.9 \mathrm{mM}$ and $\mathrm{pH}=3.0$.
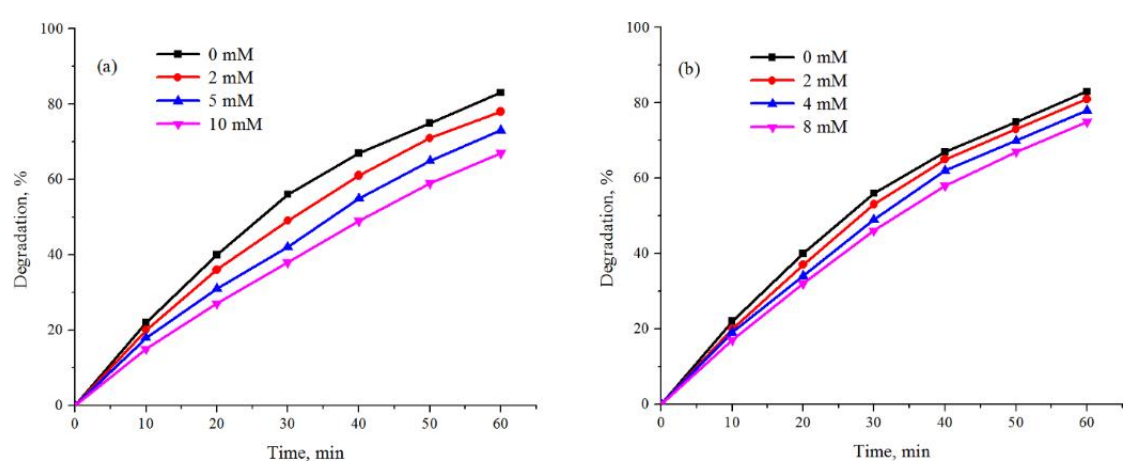

Figure 4. Effect Chloride, $\mathrm{Cl}^{-}$(a) and sulfate, $\mathrm{SO}_{4}{ }^{-}$(b) ion on \% degradation by Fenton-like process. Other experimental condition: $\left[\mathrm{H}_{2} \mathrm{O}_{2}\right]_{\mathrm{o}}=0.90 \mathrm{mM},\left[\mathrm{Fe}^{3+}\right]_{0}=[\mathrm{AY} 17]=0.06$ $\mathrm{mM}, \mathrm{pH}=3.0$ and temperature $=298 \mathrm{~K}$.

\section{Kinetic study}

To examine the degradation kinetics of acid yellow 17 by Fenton-like process, the change in absorption as a function of time data were fitted in linear integrated equations derived for zero, first, second, pseudo-first and pseudo-second-order kinetic as shown by equations given in Table $1[27,46]$. The rate constants were then calculated from the slope (in case of zero, first, second order) or intercept (in case of pseudo-second-order) of the plots (Table 2). By comparing $\mathrm{R}^{2}$ of these plots, it was suggested that the degradation of AY 17 follows the pseudo-first-order because it have better $\mathrm{R}^{2}$ value $(0.95$ or $\sim 1)$. Similarly, half-lives were also calculated using half-life equations derived for zero, first, second, pseudo-first and pseudo-second-order kinetic and appeared in first right column of Table 1. It was ascertained that the half-life value calculated through pseudo-first-order kinetic equation were closely related to experimental 
values. From these detail kinetic studies, it was concluded that the degradation of AY1 7 by Fenton-like process best fit in pseudo-first order kinetic of type.

$\mathrm{r}_{\mathrm{AY} 17}=\mathrm{k}[\mathrm{AY} 17][\mathrm{OH}] \approx \mathrm{k}^{\prime}[\mathrm{AY} 17]$

The pseudo-first-order rate constant for the degradation process of AY 17 by Fenton-like were found to be $0.0385,0.0378$ and 0.0426 at a temperature of 298,308 and $318 \mathrm{~K}$, respectively. These results have best correlation with previous literature [47].

Table 1. Integrated rate law along with half-life for various order of reaction [27, 46].

\begin{tabular}{|l|l|l|}
\hline $\begin{array}{l}\text { Order of Reaction } \\
\text { Kinetic }\end{array}$ & Equation & Half life, min \\
\hline Zeroth & $\mathrm{A}_{\mathrm{t}}=\mathrm{A}_{0}-k_{0} \mathrm{t}$ & $A_{0} / 2 k_{0}$ \\
\hline First & $\ln \mathrm{A}_{\mathrm{t}}=\ln \mathrm{A}_{0}-k_{0} \mathrm{t}$ & $\ln 2 / k_{1}$ \\
\hline Pseudo-first & $\log \left(\mathrm{A}_{t}-\mathrm{A}_{e}\right)=\log \left(\mathrm{A}_{0}-\mathrm{A}_{e}\right)-k_{1} t / 2.303$ & $\ln 2 / k_{1}$ \\
\hline Second & $1 / \mathrm{A}_{t}=1 / \mathrm{A}_{0}+k_{2} \mathrm{t}$ & $1 / k_{2}\left[\mathrm{~A}_{0}\right]$ \\
\hline Pseudo-second & $t / \mathrm{A}_{t}=1 / k_{2} \mathrm{~A}_{e}^{2}-\left(1 / \mathrm{A}_{e}\right) \mathrm{t}$ & $0.5 \mathrm{~A}_{0} \mathrm{~A}_{e} / k_{2}\left(\mathrm{~A}_{e}-0.5 \mathrm{~A}_{0}\right)$ \\
\hline
\end{tabular}

Table 2. The kinetic rate constants for degradation of AY 17 by Fenton-like process.

\begin{tabular}{|l|c|c|c|c|}
\hline Order of kinetics & $\mathrm{T} / \mathrm{K}$ & Rate constant, unit & Half-life, $\min$ & $\mathrm{R}^{2}$ \\
\hline \multirow{3}{*}{ Zero-order } & 298 & 207 & 36.7 & 0.95 \\
\cline { 2 - 5 } & 308 & 194 & 37.8 & 0.80 \\
\cline { 2 - 5 } & 318 & 181 & 39.6 & 0.70 \\
\cline { 2 - 5 } & 298 & 375 & 23.8 & 0.99 \\
\cline { 2 - 5 } & 308 & 465 & 19.0 & 0.98 \\
\hline \multirow{3}{*}{ Pseudo first-order } & 318 & 504 & 17.7 & 0.95 \\
\cline { 2 - 5 } & 298 & 491 & 18.00 & 0.98 \\
\hline \multirow{3}{*}{ Second-order } & 308 & 517 & 16.27 & 0.98 \\
\cline { 2 - 5 } & 318 & 555 & 13.16 & 0.90 \\
\cline { 2 - 5 } & 298 & 833 & 6.98 & 0.85 \\
\hline \multirow{3}{*}{ Pseudo second-order } & 308 & 580 & 1.71 & 0.90 \\
\cline { 2 - 5 } & 318 & 176 & 1.07 & 0.84 \\
\cline { 2 - 5 } & 308 & 10562 & 0.81 & 0.77 \\
\hline
\end{tabular}

anit for zero order, first-order, and second-order, are $\mathrm{M} \mathrm{min}{ }^{-1}, \min ^{-1}$, and $\mathrm{M}^{-1} \cdot \mathrm{min}$, respectively.

\section{Effect of temperature}

The rate of chemical reaction, product yield and distribution critically depend upon the initial temperature of the system. In the present work the effect of temperature on rate of reaction and percent degradation were determined using temperatures range from 298 to $318 \mathrm{~K}$ (Figure 5a). It was recorded that rise in temperature not only increased percent degradation, but also the rate of reaction. This phenomenon might be explained in term of $\bullet \mathrm{OH}$ generation as a function of temperature. It was suggested that the rise in temperature accelerates the reaction between $\mathrm{H}_{2} \mathrm{O}_{2}$ and $\mathrm{Fe}^{3+}$, hence the generation of oxidizing species like ${ }^{\bullet} \mathrm{OH}$ radical become improved $[48,49]$. 

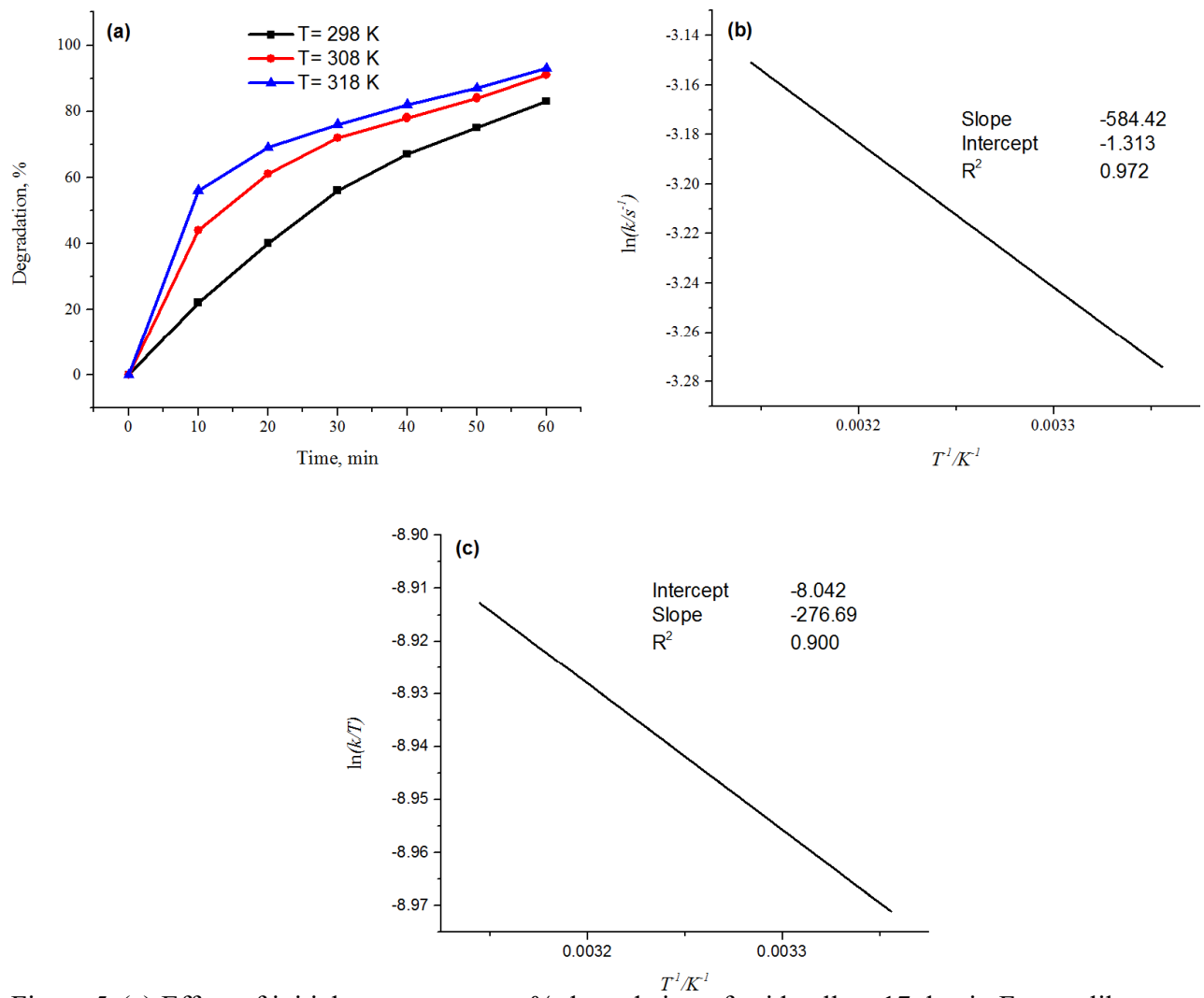

Figure 5. (a) Effect of initial temperature on \% degradation of acid yellow 17 dye in Fenton-like process, (b) $\ln \left(k / s^{-1}\right) v s . \mathrm{T}^{-1} / \mathrm{K}^{-1}$ plot, (c) $\ln (k / T) v s . \mathrm{T}^{-1} / \mathrm{K}^{-1}$ plot. Experimental condition: $\left[\mathrm{H}_{2} \mathrm{O}_{2}\right]_{\mathrm{o}}=0.90 \mathrm{mM},\left[\mathrm{Fe}^{3+}\right]_{\mathrm{o}}=[\mathrm{AY} 17]_{\mathrm{o}}=0.06 \mathrm{mM}, \mathrm{pH}=3.0$ and $\mathrm{T}=298,308$ and $318 \mathrm{~K}$.

The effect of temperature on the rate constant of the $\mathrm{H}_{2} \mathrm{O}_{2} / \mathrm{Fe}^{3+}$ system was determined by using eq. 10-11. The activation energy (Ea), enthalpy $\left(\triangle H^{\#}\right)$, and entropy $\left(\triangle S^{\#}\right)$ of activation of the $\mathrm{H}_{2} \mathrm{O}_{2} / \mathrm{Fe}^{3+}$ process was obtained by employing (see Figure $5 \mathrm{~b}$ and $\mathrm{c}$ )

$\ln k=\ln A-\frac{E_{a}}{R T}$

$\ln \frac{k}{T}=\ln \frac{\kappa k_{B}}{h}+\frac{\Delta S^{*}}{R}-\frac{\Delta H^{*}}{R} \frac{1}{T}$

Where slope $=\Delta H / R$ and intercept $=\left[\ln \left(\mathrm{kk}_{\mathrm{B}} / \mathrm{h}\right)\right]+\left(\Delta \mathrm{S}^{\#} / \mathrm{R}\right), \kappa$ is usually taken as $1, \mathrm{R}$ is universal gas constant, $\mathrm{k}_{B}$ is the Boltzmann constant and $\mathrm{h}$ is the Planck's constant. The thermodynamic parameters calculated through above equation (10 and 11) are collected in Table 4. 
Table 4. Thermodynamic parameters for the degradation of AY 17 by Fenton-like oxidation pseudo-first-order.

\begin{tabular}{|c|c|c|}
\hline $\mathrm{E}_{\mathrm{a}}, \mathrm{kJmol}^{-1}$ & $\Delta \mathrm{H}^{*}, \mathrm{kJmol}^{-1}$ & $\Delta \mathrm{S}^{*}, \mathrm{~kJ} \mathrm{~mol}^{-1} \mathrm{~K}^{-1}$ \\
\hline 4.85 & 2.30 & -0.264 \\
\hline
\end{tabular}

Comparison between standard sample prepared in triply deionized water and natural water sample

A comparative study was performed between standard and natural water sample containing AY 17 dye. The result was shown in Figure 6 which clearly shows that the degradation is maximum in standard sample as compared to natural water sample. The aqueous mediums of natural water sample were further analyzed by ion chromatography (IC). It was found that certain anions such as $\mathrm{HCO}_{3}{ }^{-}(0.298 \mathrm{mM}), \mathrm{CO}_{3}{ }^{2-}(0.252 \mathrm{mM}), \mathrm{SO}_{4}{ }^{2-}(0.5 \mathrm{mM})$, and $\mathrm{Cl}^{-}(0.335 \mathrm{mM})$ are present in aqueous medium therefore, the low degradation was due to the presence of these anions. As mentioned earlier, these anions act as scavengers of hydroxyl radical radicals. In natural water sample about $66 \%$ while in standard sample, $83 \%$ degradation achieved in $60 \mathrm{~min}$. These results suggested that photo-Fenton-like process is relatively efficient method for the degradation of AY-17 in both natural and model sample [22].

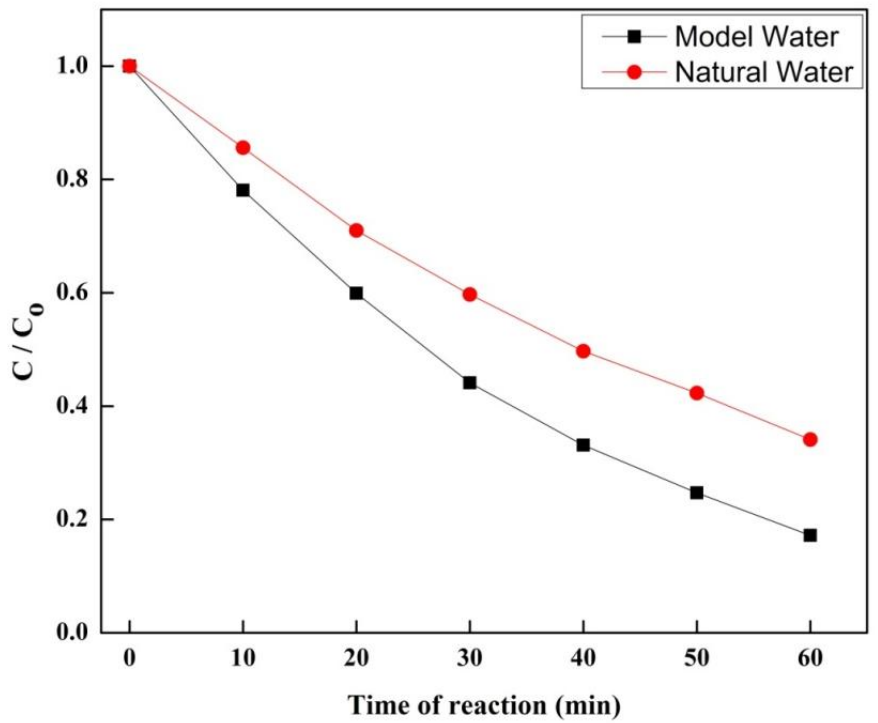

Figure 6. Effect of sulfate ions on degradation of AY 17 dye in Fenton-like process. Experimental condition: $[\mathrm{AY} 17]_{0}=\left[\mathrm{Fe}^{3+}\right]_{0}=0.06 \mathrm{mM},\left[\mathrm{H}_{2} \mathrm{O}_{2}\right]_{0}=0.90 \mathrm{mM}, \mathrm{pH}=3.0$, $\mathrm{T}=298 \mathrm{~K}$

\section{CONCLUSION}

It was concluded that the Fenton-like process is simple and cost-effective method for degradation AY-17 dye. The percent degradation of AY-17 dye is found to be $66 \%$ and $83 \%$ in natural water sample and standard sample, respectively. The low degradation in natural water sample is due to scavenging of ${ }^{\circ} \mathrm{OH}$ by various anions $\left(\mathrm{CO}_{3}{ }^{2-} \mathrm{HCO}_{3}^{-}, \mathrm{Cl}^{-}\right.$, and $\left.\mathrm{SO}_{4}^{-}\right)$, which 
normally present in natural water sample. The rise in temperature also increases percent degradation of dye.

\section{ACKNOWLEDGEMENT}

The authors highly acknowledge Higher Education Commission of Pakistan for providing funds for research and development.

\section{REFERENCES}

1. Lam, F.L.Y.; Hu, X.; Lee, T.M.H.; Chan, K.Y. A combined technique of photo-doping and MOCVD for the development of heterogeneous photo-Fenton catalyst. Sep. Purif. Technol. 2009, 67, 233-237.

2. Dutta, S.; Parsons, S.A.; Bhattacharjee, C.; Jarvis, P.; Datta, S.; Bandyopadhyay, S. Kinetic study of adsorption and photo-decolorization of reactive red 198 on $\mathrm{TiO}_{2}$ surface. Chem. Eng. J. 2009, 155, 674-679.

3. He, Z.; Lin, L.; Song, S.; Xia, M.; Xu, L.; Ying, H.; Chen, J. Mineralization of C.I. reactive blue 19 by ozonation combined with sonolysis: Performance optimization and degradation mechanism. Sep. Purif. Technol. 2008, 62, 376-381.

4. Zewge, F.; Krol, R. van de; Appel, P.W. Photoelectrocatalytic removal of color from water using $\mathrm{TiO}_{2}$ and $\mathrm{TiO}_{2} / \mathrm{Cu}_{2} \mathrm{O}$ thin film electrodes under low light intensity. Bull. Chem. Soc. Ethiop. 2008, 22, 27-40.

5. Welderfael, T.; Yadev, O.P.; Taddesse, A.M.; Kaushal, J. Synthesis, characterization and photocatalytic activities of Ag-N-codoped zno nanoparticles for degradation of methyl red. Bull. Chem. Soc. Ethiop. 2013, 27, 221-232.

6. Punjabi, P.B.; Ameta, R.; Kumar, A.; Jain, M. Visible light induced photocatalytic degradation of some xanthene dyes using immobilized anthracene. Bull. Chem. Soc. Ethiop. 2008, 22, 361-368.

7. Aregahegn, Z.; Guesh, K.; Chandravanshi, B.S.; Pérez, E. Application of chemometric methods to resolve intermediates formed during photocatalytic degradation of methyl orange and textile wastewater from ethiopia. Bull. Chem. Soc. Ethiop. 2017, 31, 223-232.

8. Bokare, A.D.; Choi, W. Review of iron-free fenton-like systems for activating $\mathrm{H}_{2} \mathrm{O}_{2}$ in advanced oxidation processes. J. Hazard. Mater. 2014, 275, 121-135.

9. Ranjithkumar, V.; Sangeetha, S.; Vairam, S. Synthesis of magnetic activated carbon $/ \alpha-\mathrm{Fe}_{2} \mathrm{O}_{3}$ nanocomposite and its application in the removal of acid yellow 17 dye from water. $J$. Hazard. Mater. 2014, 273, 127-135.

10. Aqeel, M.; Hussain, M.; Mahmood, K.; Wajid, A.; Yusof, M.; Alias, Y.; Yusoff, I. Removal of acid yellow-17 dye from aqueous solution using eco-friendly biosorbent. Desalin. Water. Treat. 2013, 51, 4530-4545.

11. Gao, J.; Zhang, Q.; Su, K.; Chen, R.; Peng, Y. Biosorption of acid yellow 17 from aqueous solution by non-living aerobic granular sludge. J. Hazard. Mater. 2010, 174, 215-225.

12. Mahdiani, M.; Soo, F.; Ansari, F.; Salavati-niasari, M. Grafting of $\mathrm{CuFe}_{12} \mathrm{O}_{19}$ nanoparticles on CNT and graphene: Eco-friendly synthesis, characterization and photocatalytic activity. J. Clean. Prod. 2018, 176, 1185-1197.

13. Ghanbari, M.; Ansari, F.; Salavati-niasari, M. Simple synthesis-controlled fabrication of thallium cadmium iodide nanostructures via a novel route and photocatalytic investigation in degradation of toxic dyes. Inorganica Chim. Acta 2017, 455, 88-97.

14. Ansari, F.; Sobhani, A.; Salavati-niasari, M. Simple sol-gel synthesis and characterization of new $\mathrm{CoTiO}_{3} / \mathrm{CoFe}_{2} \mathrm{O}_{4}$ nanocomposite by using liquid glucose, maltose and starch as fuel, capping and reducing agents. J. Colloid Interface Sci. 2018, 514, 723-732.

15. Sharma, S.; Mukhopadhyay, M.; Murthy, Z.V.P. Treatment of chlorophenols from wastewaters by advanced oxidation processes. Sep. Purif. Rev. 2013, 42, 263-295. 
16. Ghatak, H.R. Advanced oxidation processes for the treatment of biorecalcitrant organics in wastewater. Crit. Rev. Environ. Sci. Technol. 2014, 44, 1167-1219.

17. El Hajjouji, H.; Barje, F.; Pinelli, E.; Bailly, J.R.; Richard, C.; Winterton, P.; Revel, J.C.; Hafidi, M. Photochemical UV/TiO 2 treatment of olive mill wastewater (OMW). Bioresour. Technol. 2008, 99, 7264-7269.

18. Amat, A.M.; Arques, A.; Beneyto, H.; García, A.; Miranda, M.A.; Seguí, S. Ozonisation coupled with biological degradation for treatment of phenolic pollutants: A mechanistically based study. Chemosphere 2003, 53, 79-86.

19. Karunakaran, C.; Anilkumar, P. Semiconductor-catalyzed solar photooxidation of iodide ion. J. Mol. Catal. A Chem. 2007, 265, 153-158.

20. Duarte, F.; Maldonado-Hódar, F.J.; Madeira, L.M. Influence of the characteristics of carbon materials on their behaviour as heterogeneous fenton catalysts for the elimination of the azo dye orange ii from aqueous solutions. Appl. Catal. B Environ. 2011, 103, 109-115.

21. Guimarães, J.R.; Guedes Maniero, M.; Nogueira de Araújo, R. A comparative study on the degradation of RB-19 dye in an aqueous medium by advanced oxidation processes. $J$. Environ. Manage. 2012, 110, 33-39.

22. Khan, J.; Sayed, M.; Ali, F.; Khan, H.M. Removal of acid yellow 17 dye by fenton oxidation process. Z. Phys. Chem. 2018, 1-19. DOI: 10.1515/zpch-2017-1072.

23. Khan, J.; Tariq, M.; Muhammad, M.; Mehmood, M.H.; Ullah, I.; Khan, H.U.; Raziq, A.; Akbar, F.; Saqib, M.; Niaz, A. Application of photo-fenton system $\left(\mathrm{UV} / \mathrm{H}_{2} \mathrm{O}_{2} / \mathrm{Fe}^{2+}\right)$ for efficient decolorization of azo-dye acid yellow 17 in aqueous solution. Iran. J. Chem. Chem. Eng. 2018. Available at: http://www.ijcce.ac.ir/article_33280.html.

24. Yuan, S.; Gou, N.; Alshawabkeh, A.N.; Gu, A.Z. Efficient degradation of contaminants of emerging concerns by a new electro-fenton process with Ti/MMO Cathode. Chemosphere 2013, 93, 2796-2804.

25. Babuponnusami, A.; Muthukumar, K. Removal of phenol by heterogenous photo electro Fenton-like process using nano-zero valent iron. Sep. Purif. Technol. 2012, 98, 130-135.

26. Fan, X.; Hao, H.; Wang, Y.; Chen, F.; Zhang, J. Fenton-like degradation of nalidixic acid with $\mathrm{Fe}^{3+} / \mathrm{H}_{2} \mathrm{O}_{2}$. Environ. Sci. Pollut. Res. 2013, 20, 3649-3656.

27. Sun, S.; Li, C.; Sun, J.; Shi, S.; Fan, M.-H.; Zhou, Q. Decolorization of an azo dye orange G in aqueous solution by fenton oxidation process: Effect of system parameters and kinetic study. J. Hazard. Mater. 2009, 161, 1052-1057.

28. Nogueira, R.F.P.; Trovó, A.G.; Silva, M.A. da; Villa, R.D.; Oliverira, M.C. de. Fundaments and environmental applications of fenton and photo-fenton processes. Quim. Nova. 2007, 30, 400-408.

29. Ammar, H.B.; Brahim, M. Ben; Abdelhédi, R.; Samet, Y. Chemical enhanced degradation of metronidazole by sunlight via photo-fenton process under gradual addition of hydrogen peroxide. J. Mol. Catal. A. Chem. 2016, 420, 222-227.

30. Safarzadeh-Amiri, A.; Bolton, J.R.; Cater, S.R. The use of iron in advanced oxidation processes. J. Adv. Oxid. Technol. 1996, 1, 18-26.

31. Sun, Y.; Pignatello, J.J. Photochemical reactions involved in the total mineralization of 2,4D by iron(3+)/hydrogen peroxide/UV. Environ. Sci. Technol. 1993, 27, 304-310.

32. Lin, S.H.; Chuang, T.S. Combined treatment of phenolic wastewater by wet air oxidation and activated sludge. Toxicol. Environ. Chem. 2008, 44, 243-258.

33. Siedlecka, E.M.; Mrozik, W.; Kaczyński, Z.; Stepnowski, P. Degradation of 1-butyl-3methylimidazolium chloride ionic liquid in a fenton-like system. J. Hazard. Mater. 2008, 154, 893-900.

34. Gallard, H.; De Laat, J.; Legube, B. Spectrophotometric study of the formation of iron(III)hydroperoxy complexes in homogeneous aqueous solutions. Water Res. 1999, 33, 29292936.

35. Plgnatello, J.J. Dark and photoassisted $\mathrm{Fe}^{3+}$-catalyzed degradation of chlorophenoxy 
herbicides by hydrogen peroxide. Environ. Sci. Technol. 1992, 26, 944-951.

36. Pignatello, J.J.; Oliveros, E.; MacKay, A. Advanced oxidation processes for organic contaminant destruction based on the fenton reaction and related chemistry. Crit. Rev. Environ. Sci. Technol. 2006, 36, 1-84.

37. Brillas, E.; Sire, I.; Oturan, M. A.; Sirés, I.; Oturan, M.A. Electro-Fenton process and related electrochemical technologies based on Fenton's reaction chemistry. Chem. Rev. 2009, 109, 6570-6631.

38. Wang, J.L.; Xu, L.J. Advanced oxidation processes for wastewater treatment: formation of hydroxyl radical and application. Crit. Rev. Environ. Sci. Technol. 2012, 42, 251-325.

39. Rivas, F.J.; Beltrán, F.J.; Frades, J.; Buxeda, P. Oxidation of $p$-hydroxybenzoic acid by Fenton's reagent. Water Res. 2001, 35, 387-396.

40. Ghoneim, M.M.; El-Desoky, H.S.; Zidan, N.M. Electro-Fenton oxidation of sunset yellow FCF azo-dye in aqueous solutions. Desalination 2011, 274, 22-30.

41. Fenoll, J.; Martínez-Menchón, M.; Navarro, G.; Vela, N.; Navarro, S. Photocatalytic degradation of substituted phenylurea herbicides in aqueous semiconductor suspensions exposed to solar energy. Chemosphere 2013, 91, 571-578.

42. Burbano, A.A.; Dionysiou, D.D.; Suidan, M.T.; Richardson, T.L. Oxidation kinetics and effect of ph on the degradation of MTBE with Fenton reagent. Water Res. 2005, 39, 107118.

43. Riga, A.; Soutsas, K.; Ntampegliotis, K.; Karayannis, V.; Papapolymerou, G. Effect of system parameters and of inorganic salts on the decolorization and degradation of procion $\mathrm{H}$-Exl dyes. comparison of $\mathrm{H}_{2} \mathrm{O}_{2} / \mathrm{UV}$, Fenton, UV/Fenton, $\mathrm{TiO}_{2} / \mathrm{UV}$ and $\mathrm{TiO}_{2} / \mathrm{UV} / \mathrm{H}_{2} \mathrm{O}_{2}$ processes. Desalination 2007, 211, 72-86.

44. Kochany, J.; Lipczynska-Kochany, E. Application of the EPR spin-trapping technique for the investigation of the reactions of carbonate, bicarbonate, and phosphate anions with hydroxyl radicals generated by the photolysis of $\mathrm{H}_{2} \mathrm{O}_{2}$. Chemosphere 1992, 25, 1769-1782.

45. Devi, L.G.; Munikrishnappa, C.; Nagaraj, B.; Rajashekhar, K.E. Effect of chloride and sulfate ions on the advanced photo Fenton and modified photo Fenton degradation process of alizarin red S. J. Mol. Catal. A Chem. 2013, 374-375, 125-131.

46. Karatas, M.; Argun, A.Y.; Argun, E.M. Decolorization of antraquinonic dye, reactive blue 114 from synthetic wastewater by Fenton process: Kinetics and thermodynamics. J. Ind. Eng. Chem. 2012, 18, 1058-1062.

47. Xu, H.; Yu, T.; Wang, J.; Xu, A. Degradation kinetic of reactive red azo dye by Fenton-like process using online spectrophotometric method. Fresenius Environ. Bull. 2016, 25, 2154 2165.

48. Sun, J.; Sun, S.; Wang, G.; Qiao, L. Degradation of azo dye amido black 10B in aqueous solution by Fenton oxidation process. Dye. Pigment. 2007, 74, 647-652.

49. Idel-aouad, R.; Valiente, M.; Yaacoubi, A.; Tanouti, B.; López-Mesas, M. Rapid decolourization and mineralization of the azo dye C.I. acid red 14 by heterogeneous Fenton reaction. J. Hazard. Mater. 2011, 186, 745-750. 